\title{
Determination of Nutrition Knowledge of Adolescents Engaged in Sports
}

\author{
Ayşe Kudret Saribay ${ }^{1}$, Şule Kirbaş̧ ${ }^{2, *}$ \\ ${ }^{1}$ Institute of Medical Sciences, Amasya University, Turkey \\ ${ }^{2}$ Department of Physical Education and Sports Teaching, Faculty of Education, Amasya University, Turkey
}

Copyright $\odot 2019$ by authors, all rights reserved. Authors agree that this article remains permanently open access under the terms of the Creative Commons Attribution License 4.0 International License

\begin{abstract}
This study was carried out to determine the nutritional knowledge of adolescents engaged in sports at the high school level in the central schools in Şanlıurfa. Sample of study was 495 students randomly selected who are engaged in sports in 4 high schools in Şanliurfa. Verbal consent of the participants and institution permit were taken for the study. Nutrition Knowledge Scale for Adolescents (NKSA) was used for data collection and Statistical Package for the Social Sciences (SPSS) 23 package was used for data analysis. Descriptive statistics, independent samples t-test, one-way analysis of variance, Turkey Honest Significant Difference (HSD) test and Games-Howell test were used to evaluate the data. In the analysis, Type I error margin was accepted as 0.05.No significant difference was found in the average scores of nutrition knowledge levels in gender, age, sport type-duration, number of family members, body mass index (BMI) $(\mathrm{p}>0.05)$. A significant difference was found when the school type and income level variables of the participants were examined $(p<0.001)$. It was found that approximately $65 \%$ of the students have low level of nutritional knowledge. As a result, it was determined that the majority of the participants in our study had low nutritional knowledge and that income levels and school type affect the level of knowledge. In this respect, it is thought that seminars, which will be organized in cooperation with gym teachers aiming to increase the nutritional knowledge of young people in schools and clubs will be beneficial.
\end{abstract}

Keywords Sport, Adolescent, Nutrition, Knowledge

\section{Introduction}

Nutrition is performed by the person in a conscious manner to protect and improve health and to improve the quality of life of the body by taking sufficient amount of nutrients needed by the body at the right time [1].
Adolescence is a transition period from childhood to adulthood [2]. Feeding sufficient amounts of energy and nutrients during this period, in which the rate of growth and development increased ensures that the individual is at the same level of development as his/ her peers[3]. Physical changes in this period affect and change the body's nutritional needs. In addition to increasing need of energy, protein, vitamins and minerals, an increased appetite is observed, too [1].

Nutrition for adolescent athletes is important and necessary to ensure both sporting success and continuation of growth and development [4]. Although nutrition problems of young athletes are thought to be parallel to that of adult athletes, nowadays, it is known that they have a variety of physiological and metabolic features that distinguish the growing children from adults and require specific nutritional factors [5]. Nutritional recommendations should be based on the latest scientific data [6].

Additional energy needs should be calculated according to the sports branch of adolescents in the adolescent period and this energy should be given as an extra. It should be also kept in mind that pre and post-sport nutrition affects performance [7]. When exposed to hard workouts or strict diets, the development of adolescents can slow down and sport can damage their development [8]. Correct training, nutrition and genetic inheritance are factors affecting the performance of athletes in general. The fact that athletes have information about nutrition allows them to keep their diet under control and to make interventions that may affect their performance [9].The enlightenment of athletes about the need of energy and nutrient allows them to reach the highest performance level [10].

Since nutrition knowledge is important both for development and sporting performance of adolescents, on the basis of contribution of determination the nutrition knowledge to sport and development, in our study, we aimed to determine the nutritional knowledge of adolescents at high school level engaged in sports in the central schools of Şanliurfa. 


\section{Material and Method}

The research is a descriptive study on 495 students engaged in sports in 4 randomly selected high schools between the dates of December 2017- February 2018 in Şanliurfa province. A personal information form consisting of 12 questions was used to determine the personal characteristics of adolescent athletes and Nutrition Knowledge Scale for Adolescents (NKSA), which is developed by Öz et al. and consists of three sub-dimensions of adequate and balanced nutrition, nutrition-related health problems and essential nutrients, was used to determine nutritional knowledge of adolescent athletes [11].

12 of the propositions were false suggestions and 1 point was given to each correct answer. Inaccurate propositions were reverse coded. There are 9 recommendations for adequate and balanced diet, 21 for food items, and 8 for nutrient related health problems. The maximum score that can be taken from the NKSA questionnaire is 38, while the minimum score is 0 points. According to the validity and reliability results of the NKSA questionnaire, the difficulty index for adequate and balanced nutrition sub-area is between $31.01 \%$ and $83.54 \%$ and the discriminator index is between $0.24-0.36$. In the sub-area of nutrition-related health problems, the difficulty index is $61.39 \%-83.75 \%$ and the discriminator index is $0.28-0.49$. As a result of the evaluation of the questionnaire sections, Cronbach's alpha value was found as 0.62 in the sub-dimension of adequate and balanced nutrition, 0.78 in the basic food items sub-dimension and 0.70 in the nutrition-related disorders sub-dimension. The internal consistency coefficient of the questionnaire was Cronbach alpha: 0.85 and it was found as highly reliable. Spearman rank correlation analysis of the questionnaire was found as 0.69 [11]. The data obtained from the scale were evaluated by means of given correct and incorrect answers. Nutritional knowledge levels of the participants were scored by giving 1 point for each correct answer and 0 point for each wrong answer.

All anthropometric measurements were taken using standardized techniques and calibrated equipment. The anthropometric measurement was taken after the participant's shoes, extra weights and clothes were taken off. Participants' body height (in $\mathrm{cm}$ ) was measured using a stadiometer (Seca 214, Germany) calibrated in millimeters and their body weight (in $\mathrm{kg}$ ) was obtained using a balance beam scale (Seca 700, Germany). According to obtained data, each participant's BMI was computed using the following formula: body mass $(\mathrm{kg}) /$ height $^{2}(\mathrm{~m})$.

Data analysis was conducted by SPSS 23 package. Before performing analysis, initial analyzes were performed according to the recommendations of Hair, Black, Babin and Anderson [12]. First of all, the minimum and maximum values in the data set and the frequency distributions of the variables were examined, as well. It was seen that all variables were in the expected range of values. In the second stage, the missing values in the data set were examined and no missing value was found in the data set. In the third stage, the outliers in the data set were examined. For this purpose, total scores of the participants in NKSA scale were converted to $\mathrm{z}$ scores and the criteria proposed by Tabachnick and Fidell [13] were used to determine outliers. According to Tabachnick and Fidell [13], $\mathrm{z}$ scores of -3.29 and below, or +3.29 or above, is considered as an outlier.

\section{Findings}

The study was completed with 495 adolescent athletes aged between 14 and 19 years. Out of 495 individuals, 197 (39.8\%) of them engaged in football; 64 (12.9\%) basketball; $58(11.7 \%)$ volleyball; $50(10.1 \%)$ athletics; $26(5.3 \%)$ handball and $100(20.2 \%)$ other sports.

The majority of the students participated in research were male $(79.8 \%)$ and mostly 15 years old $(30.3 \%)$. On the other hand, a limited number of students attend the Vocational and Technical High School (13,9\%) and Handball players (5,3\%). 21,2\% of the students have been doing sports for two years. The family income of the majority of the students was 801 TL to 1600 TL (41.4\%), while the number of people in the family was 7 and over $(40 \%)$. Finally, students had normal body mass indexes according to the classification proposed by the World Health Organization (WHO, 2000). Seen in Table 1, approximately $65 \%$ of the students $(n=323)$ had a low level of nutritional knowledge, while $35 \%(n=172)$ had an adequate level of nutritional knowledge. 
Table 1. Descriptive Statistics Showing the Nutrition Knowledge of Adolescents Engaged in Sport

\begin{tabular}{|c|c|c|}
\hline & $\mathbf{N}$ & $\%$ \\
\hline \multicolumn{3}{|l|}{ Gender } \\
\hline Male & 395 & 79.8 \\
\hline Female & 100 & 20.2 \\
\hline \multicolumn{3}{|l|}{ Age } \\
\hline 14 & 67 & 13.5 \\
\hline 15 & 150 & 30.3 \\
\hline 16 & 128 & 25.9 \\
\hline 17 & 112 & 22.6 \\
\hline 18 and over & 38 & 7.7 \\
\hline \multicolumn{3}{|l|}{ School Type } \\
\hline Sport High School & 147 & 29.7 \\
\hline Anatolian High School & 128 & 25.9 \\
\hline College & 151 & 30.5 \\
\hline Vocational and Technical H.S. & 69 & 13.9 \\
\hline \multicolumn{3}{|l|}{ Sport Type } \\
\hline Football & 197 & 39.8 \\
\hline Basketball & 64 & 12.9 \\
\hline Volleyball & 58 & 11.7 \\
\hline Athletics & 50 & 10.1 \\
\hline Handball & 26 & 5.3 \\
\hline Other & 100 & 20.2 \\
\hline \multicolumn{3}{|l|}{ Duration of Sport } \\
\hline 1 year & 114 & 23.0 \\
\hline 2 years & 105 & 21.2 \\
\hline 3 years & 80 & 16.2 \\
\hline 4 years & 56 & 11.3 \\
\hline 5 years and over & 140 & 28.3 \\
\hline \multicolumn{3}{|l|}{ Monthly Income } \\
\hline $800 \mathrm{TL}$ and less & 89 & 18.0 \\
\hline $801-1600 \mathrm{TL}$ & 205 & 41.4 \\
\hline $1601-2400 \mathrm{TL}$ & 109 & 22.0 \\
\hline 2401-3200 TL & 36 & 7.3 \\
\hline $3201 \mathrm{TL}$ and more & 56 & 11.3 \\
\hline \multicolumn{3}{|l|}{ Number of Family Members } \\
\hline 4 and below & 95 & 19.2 \\
\hline 5 & 86 & 17.4 \\
\hline 6 & 116 & 23.4 \\
\hline 7 and over & 198 & 40.0 \\
\hline \multicolumn{3}{|l|}{ Body Mass Index (BMI) } \\
\hline Underweight (18.49 and under) & 122 & 24.6 \\
\hline Normal (between 18.50-24.99) & 340 & 68.7 \\
\hline Overweight (25.00 and over) & 33 & 6.7 \\
\hline \multicolumn{3}{|l|}{ Nutrition Knowledge } \\
\hline Inadequate & 323 & 65.3 \\
\hline Adequate & 172 & 34.7 \\
\hline
\end{tabular}


Table 2. Comparison of nutrition knowledge score between genders using student t-test

\begin{tabular}{ccccc}
\hline Gender & $\mathrm{n}$ & Avg $\pm S S$ & $T$ & $P$ \\
\hline Male & 395 & $19.98 \pm 4.79$ & 0.84 & 0.401 \\
\hline Female & 100 & $20.44 \pm 5.27$ & & \\
\hline
\end{tabular}

Note: $\mathrm{N}=495$.

There was no significant difference between the average scores of nutritional knowledge levels of females and males who participated in the study $(t=0.84, p>0.05)$.

Table 3. Comparison of nutrition knowledge score between age groups, school variables, sport categories, sport duration categories, income categories, number of family member categories, body mass index categories using one-way ANOVA

\begin{tabular}{|c|c|c|c|c|}
\hline Age & $\mathbf{n}$ & $\operatorname{Avg} \pm S S$ & $\boldsymbol{F}$ & $\boldsymbol{P}$ \\
\hline 1. 14 & 67 & $19.75 \pm 4.90$ & \multirow{5}{*}{0.32} & \multirow{5}{*}{0.864} \\
\hline 2. 15 & 150 & $20.19 \pm 4.35$ & & \\
\hline 3. 16 & 128 & $20.00 \pm 5.53$ & & \\
\hline 4. 17 & 112 & $20.37 \pm 4.82$ & & \\
\hline 5. $18^{+}$ & 38 & $19.53 \pm 4.96$ & & \\
\hline \multicolumn{5}{|c|}{ School Type } \\
\hline 1. Sport High School & 147 & $18.90_{\mathrm{b}} \pm 4.96_{\mathrm{b}}$ & \multirow{4}{*}{11.404} & \multirow{4}{*}{$0.001 *$} \\
\hline 2. Anatolian High School & 128 & $20.59_{\mathrm{a}} \pm 4.52_{\mathrm{a}}$ & & \\
\hline 3. College & 151 & $21.56_{a} \pm 4.16$ & & \\
\hline 4. Vocational and Technical H.S. & 69 & $18.36_{b} \pm 5.76$ & & \\
\hline \multicolumn{5}{|c|}{ Sport Type } \\
\hline 1. Football & 197 & $20.39 \pm 4.89$ & \multirow{6}{*}{2.00} & \multirow{6}{*}{0.077} \\
\hline 2. Basketball & 64 & $19.84 \pm 5.65$ & & \\
\hline 3. Volleyball & 58 & $19.21 \pm 4.57$ & & \\
\hline 4. Athletics & 50 & $19.86 \pm 5.15$ & & \\
\hline 5. Handball & 26 & $17.92 \pm 5.33$ & & \\
\hline 6. Other & 100 & $20.76 \pm 4.10$ & & \\
\hline \multicolumn{5}{|c|}{ Sporting Time } \\
\hline 1. 1 year & 114 & $19.92 \pm 4.73$ & \multirow{5}{*}{1.10} & \multirow{5}{*}{0.358} \\
\hline 2. 2 years & 105 & $19.46 \pm 4.95$ & & \\
\hline 3. 3 years & 80 & $20.84 \pm 4.53$ & & \\
\hline 4. 4 years & 56 & $20.59 \pm 4.45$ & & \\
\hline 6. 5 years and over & 140 & $20.01 \pm 5.30$ & & \\
\hline \multicolumn{5}{|c|}{ Family Income } \\
\hline 1. $800 \mathrm{TL}$ and less & 89 & $18.60_{b} \pm 5.57$ & \multirow{5}{*}{5.02} & \multirow{5}{*}{$0.001 *$} \\
\hline 2. $801-1600 \mathrm{TL}$ & 205 & $21.05_{\mathrm{a}} \pm 4.54$ & & \\
\hline 3. $1601-2400 \mathrm{TL}$ & 109 & $19.53_{\mathrm{a}} \pm 4.80$ & & \\
\hline 4. $2401-3200 \mathrm{TL}$ & 36 & $20.81_{\mathrm{a}} \pm 3.83$ & & \\
\hline 5. $3201 \mathrm{TL}$ and over & 56 & $19.43_{\mathrm{a}} \pm 5.03$ & & \\
\hline \multicolumn{5}{|c|}{ Number of Family Members } \\
\hline 1. 4 persons and under & 95 & $20.47 \pm 5.01$ & \multirow{4}{*}{0.81} & \multirow{4}{*}{0.491} \\
\hline 2. 5 & 86 & $19.77 \pm 5.05$ & & \\
\hline 3. 6 & 116 & $20.47 \pm 4.37$ & & \\
\hline 4. 7 and over & 198 & $19.78 \pm 5.05$ & & \\
\hline \multicolumn{5}{|c|}{ Body Mass Index } \\
\hline 1. Underweight & 122 & $19.80 \pm 5.15$ & \multirow{3}{*}{0.35} & \multirow{3}{*}{0.491} \\
\hline 2. Normal & 340 & $20.12 \pm 4.76$ & & \\
\hline 5. Overweight & 33 & $20.51 \pm 5.25$ & & \\
\hline
\end{tabular}

Note: $p<0.001^{*}, \mathrm{a}>\mathrm{b}$. There is no difference between the groups bearing the same letter in the same column. (School Type, Family Income)

There were a significant difference in terms of the average scores of the knowledge of the students depending on school types $(F(3,491)=11.04, p<0.001)$ and family monthly income levels $(F(3,491)=11.04, p<0.001)$. But there were no significant difference in terms of the average scores of the knowledge of the adolescent athletes between age groups $(F(4$, $490)=.32, p>0.05)$, sport categories $(F(5,489)=2.00, p>0.05)$, duration of sport categories $(F(4,490)=1.10, p>0.05)$, number of family members $(F(3,491)=0.81, p>0.05)$ and body mass index classification $(F(3,491)=0.81, p>0.05)$. 


\section{Discussion}

Nutrition is a factor that plays an important role in sports performance as well as optimal growth and development in adolescents. Macronutrients, micronutrients and fluid intake should be taken in appropriate amounts and form to provide the energy needed for growth and performance [14]. In our study, based on the importance of this issue and the need to take more consideration in terms of youth setup athletes, the average score of nutritional knowledge of the male and female students engaged in sports was compared. The average score of nutritional knowledge of females was 19.98 (s.d: 4,79), while the mean score of males was 20.44 (s.d: 5,27). There was no significant difference between the level of nutrition knowledge of adolescents engaged in sports according to gender.

Kaya [15] could not find a significant difference in terms of nutrition knowledge between genders in his study conducted on a total of 264 students with an average age of 16,5 in Seyhan, Sarıçam and Çukurova districts of Adana province. In the same way, in the studies conducted by Ak1 and Gürbüz [16], Süel et al. [17] and Özdoğan [18], there was no significant difference in terms of nutrition knowledge of the athletes according to the gender variable in parallel with our study. Webb and Beckford [19] could not find a significant difference in terms of gender in their study conducted on a total of 220 swimmer adolescents, 98 of whom were females and 122 of them were males from different ethnic backgrounds (Africa, Asia, India, Caucasian and Hybrid) with an average age of 14. In another study conducted on 47 licensed swimmers aged 10-18 years to determine the levels of nutritional knowledge, no significant difference was found in terms of the nutritional knowledge levels of the athletes between genders [20].These studies support our work.

However, in the study conducted by Şanlier et al. [21] with a total of 1340 students, 609 of whom are males and 122 of whom are females. In order to determine the levels of nutritional knowledge of the students, unlike our study, it was found that the females' nutrition knowledge scores were higher than the males'. Similarly, in a study conducted by Karasu [22], adolescent female students' nutritional knowledge was found to be higher than that of males; besides, in another study conducted by Hellert et al. [23], 3546 adolescents aged 12-18 years were found to have increased nutritional knowledge with age and female students' nutritional knowledge was found to be higher than that of males. Unlike our work, these studies indicate that gender affects nutritional knowledge. Nutritional knowledge level of athletes in our study group did not differ according to gender. This may be due to the fact that the same trainer or physical education teacher provided training to groups regardless of gender.

In our study, when the scores of nutrition knowledge according to the age were examined, no significant difference was found in the average score of the students' nutritional knowledge. The study conducted by Webb and Beckford [19] also supports our study and they stated that there was no significant difference between ages in terms of nutrition knowledge levels.

In a study conducted by Akıl and Gürbüz [16], a significant difference was found in terms of age variables. In this study, it is reported that the level of nutritional knowledge increases as the age increases. In another study, it was found that there was a statistically significant difference between the average nutrition knowledge scores of the grade they attended and the age [18], this case differs from our study. This may be due to the fact that adolescent athletes participating in our study are not subject to adequate nutrition education and may be the result of giving the same training to each age group in terms of behaviors and attitudes that they depict.

In a study conducted in 2006, unlike the study of Ak1 and Gürbüz [16], it was found that the level of knowledge of high school students with older ages was lower. According to this, it can be said that there are differences in nutrition knowledge of high school students in different age groups or age variable affects the knowledge level of high school students [22].In fact, the expected situation is that the level of knowledge increases as the age and education level increase. However, based on the results of the research, it can be said that the expected result due to the given training is often not reached.

It can be thought that the difference in the results may be caused by the place where the working groups live, the difference between the school they attend and the education they have. Increasing nutritional knowledge will contribute to the improvement of nutritional habits, improved diet will ensure better health and finally, a better health will support individual and team performance at the best level[24].

In our study, the average score of nutrition knowledge of the adolescents engaged in sports according to the type of school showed a statistically significant difference. It was observed that the level of nutrition knowledge of the students attending the sport high school and the students attending the vocational high schools were similar, besides, the level of nutritional knowledge of the two schools was found to be significantly lower than that of Anatolian high school students and high school students. It is expected that the level of nutritional knowledge of sports high school students will be higher since they have the nutrition class. However, it can be thought that the reason for the opposite results could be arisen from the lack of sufficient education on nutrition related to sport and the difference between the Anatolian high schools and colleges in terms of the level of the students and the given education.

The level of nutritional knowledge of the students engaged in different types of sports participating in our study was similar. In other words, there is no significant difference in terms of the level of nutritional knowledge among the students according to the sport type variable. It 
is known that different sports branches have different energy needs and athletes should be fed accordingly. However, it can be said that the athletes in our study group do not have the specific nutritional knowledge and as a result, it can be said that there is no significant difference according to the type of sport.

In a study conducted by Çırak [25] on licensed adolescent athletes aged 12-17 in athletics, wrestling, judo, karate and badminton branches. When the nutrition knowledge is examined, unlike our work, it was determined that the nutritional knowledge levels of judo, badminton and karate athletes respectively had the highest score and there was a significant difference in nutrition knowledge level between branches. It may be thought that the difference may be the result of the training given by the coaches.

In our study, there was no statistically significant difference in terms of the nutritional knowledge levels of adolescent athletes between duration of sports categories. However, in a study conducted in 2005, unlike our study, it was reported that the level of nutritional knowledge increased as duration of sports increased [16]. Normally the expected result is an increase in the knowledge and skills of the athlete as the sports experience increases.

According to the family monthly income level of the adolescent participants, the average scores of nutrition knowledge level shows a significant difference. It was found that the level of nutritional knowledge of the students whose family income was between 801-1600 TL was significantly lower than the students whose family monthly income was $800 \mathrm{TL}$ and below. There was no significant difference between the other groups. Similar to our study, there was a significant difference in nutrition knowledge between family income level categories in the study conducted by Akıl and Gürbüz [16]. Research suggests that the level of income of athletes affects the level of nutritional knowledge [26]. Based on these results, it can be assumed that the family income level is effective on children's nutritional knowledge.

There was no significant difference in the average score of the nutrition knowledge of adolescent students at the high school level between the number of people living in the family. In other words, it has been observed that large or elementary family members do not affect the level of nutrition knowledge. However, as the number of people in the family increases, the per capita expenditures are expected to decrease in families with low purchasing power and low income. Under the circumstances, although the number of people does not differ in determining the nutritional information and habits, it is thought that the increase in the number of people will have a negative impact on the children at the healthy nutrition level depends on the economic situation of the family.

When we look at the body mass index values, it was seen that there was no significant difference in the nutrition knowledge of the adolescents engaged in sports. In other words, there is no significant difference in the average score of nutrition knowledge. In the study conducted by Şanlier et al [21], it was found that there was no statistically significant difference in nutrition knowledge and habits between BMI categories. The results support our findings.

In our study, it was determined that $65.3 \%$ of the participants had low nutritional knowledge. In a study conducted by Şimşek [27], it was observed that 398 students in the adolescent age range between 13-14 years had inadequate nutritional knowledge level. In another study conducted by Heydenreich et al. [28], it was determined that nutritional knowledge levels of 559 athletes, of whom 330 were male and 229 were female, were insufficient. In a study conducted on football players aged 14-18 years, the level of nutritional knowledge was reported to be low compared to the literature [29].

These results support our findings. However, unlike our findings, in a study conducted for determining the nutrition knowledge level of the students being active in the school teams in the high schools of Şırnak province, it was found that their nutrition knowledge was at moderate level [30]. Similarly, in another study conducted in different socio-economic regions of Ankara to determine the nutrition knowledge of the final year students of three high schools, nutritional information scores were found to be at moderate level [31]. According to the pre-training tests in a study that includes the training program for 13-18 age group without athletes and athletes; It was determined that they had moderate and high level awareness and attitude in both groups related to nutritional information [32].

It is thought that the differences may be caused by the socio-economic level of families and schools. When the literature is investigated, it is seen that there have been studies showing the fact that the level of family income affects the adolescents' nutritional knowledge [16,33].

Nutritional information is one of the main factors affecting the nutrition habits of individuals, families and communities. In general, even if the people have available food and economic resources, the lack of nutritional knowledge of the people is negatively affecting the productive use of these resources and this may lead to incorrect nutrition practices [34]. In this respect, nutritional information should not be ignored, because adequate and balanced nutrition promotes the physical growth of adolescents and the formation of a sound skeletal and muscular system. In addition to this, it is important in terms of mental development of adolescents [28]. For the health and development of adolescents in a multifaceted way, first of all, adequate and balanced nutrition should be provided starting from within the family, besides, due diligence should be exercised to ensure proper nutrition knowledge and habits of adolescents.

A diet optimized for young athletes is important for growth, health and athletic performance. For nutritional information of athletes, nutrition education programs should be particularly focused [28].Two years training 
program to encourage high school athletes to a healthy diet has been seen to improve the $\operatorname{diet}[35]$. It is also stated that the correct training programs applied to the athletes will not only create a change in the point of knowledge, but also create a behavior towards nutrition[36]. These training programs should be created primarily for families, teachers and coaches. Because, if these groups, who have an effective role in raising athletes, are adequately informed, it is thought that the athletes who will transfer the information will exhibit a more conscious feeding behavior and the level of nutritional knowledge is thought to be high.

\section{Conclusions}

As a result of the study, there was no significant difference between the average scores of the nutrition knowledge of the adolescents according to the age, gender, sport type, number of the family members, duration of sport and body mass index variables.

The average scores regarding the nutritional knowledge level of the participants according to the school type show a significant difference.

When the family monthly income levels of the adolescent athletes are examined, it is seen that participants with family income of $800 \mathrm{TL}$ and less have lower nutritional information than those with family income between 801-1600 TL.

In our study, it was found that $65.3 \%$ of the participants (323) had low nutritional knowledge, $34,7 \%$ of them had sufficient knowledge level and it was determined that the income levels and the type of school affect the knowledge level.

As a result, the basis of a healthy life is sports and nutrition. If children's nutritional knowledge is given at an early age as well as sports training, it is thought that this will contribute significantly to public health and sporting success.

\section{REFERENCES}

[1] Erkan, T. Nutrition in adolescents, Turkish Ped Archive; 46 Special Edition: 49-53, 2011.

[2] Healthy nutrition and physical activity teacher's handbook, Turkish Public Health Institution, Ankara (www. beslenme.gov.tr), 2016.

[3] Demir, H. Adolescent nutrition. J CurrPediatr; 6, 2008.

[4] Purcell, LK. Sport nutrition for young athletes. Canadian Paediatric Society;18(4):200-2, 2013.

[5] Almquist, J.,Valovich, Mc., Leod, TC., Cavanna A. Summary statement: appropriate medical care for the secondary school- aged athlete. J Athl Train; 43: 416-427, 2008 .
[6] Cotugna, N.,Vickery, CE.,McBee, S. Sports nutrition for young athletes. The Journal of School Nursing. 21(6):323-8, 2005.

[7] Özkarabulut, A.H., Yürek, M.H. Nutritional status and differences between male and female students in basketball clubs,Igusabder 3 (2017): 239-259, 2017.

[8] Rice, SG. Medical conditions affecting sports participation. American Academy of Pediatrics; 121(4):841-8, 2008.

[9] Ersoy, G., Hasbay, A. Sports nutrition, First Edition, Ankara, Sinem Printing, Ministry of Health, Ekim-2006.

[10] Hawley, J A., Tipton, KD., Millard-Stafford, ML. Promoting training adaptations through nutritional interventions. J Sports Sci 24 (7): 709-21, 2006.

[11] Öz, F., Aydin, R., Onsuz, M. F., Metintas, S. ve Emiral, G. O. Development of a reliable and valid adolescence nutritional knowledge questionnaire. Progression Nutrition, 18(2), 125-134, 2016.

[12] Hair, J.F., Black, W.C., Babin, B.J. and Anderson, R. E. Multivariate data analysis (7. bs.). Harlow: Pearson Education Limited, 2014.

[13] Tabachnick, B.G. andFidell, L.S. Using multi variate statistics (6. bs.). Harlow: Pearson Education, 2014.

[14] Otman, Ö.T. Evaluation of nutritional status and fluid consumption and caffeine intake of adolescent football players. Hacettepe University, Institute of Health Sciences, Dietetics Program, Master Thesis, Ankara, 2017.

[15] Kaya, N. Comparison of nutrition knowledge, attitudes and behaviors of students attending and non-attending school sports activities. Düzce University, Institute of Health Sciences, Department of Physical Education and Sport Sciences. Master Thesis, Düzce, 2015.

[16] Akıl, M. ve Gürbüz, Ü. Examining the nutritional knowledge of athletes engaged in throw branch.Journal of PhysicalEducation and SportSciences; Volume 7, Issue1, 2005.

[17] Süel, E., Şahin, İ., Karakaya, M.A., Savucu, Y. Nutritional knowledge and habits of elite basketball players.7th International Congress on Sport Sciences, s, il I, Antalya, 2002.

[18] Özdoğan, Y.Scale development study to determine eating behaviors and nutrition information of adolescents. Ankara University, Institute of Science and Technology, Department of Home Economics (Nutrition Sciences). PhD Thesis, Ankara, 2013.

[19] Webb, M.C. and Beckford, S.E. Nutritional knowledge and attitudes of adolescents wimmers in Trinidad and Tobago. Journal of Nutrition and Metabolism. Article ID 506434,17 pages, 2014.

[20] Duman, E.U. Determining the relationship between nutrition parameters and some parameters of 10-18 age group swimmers. Haliç University, Institute of Health Sciences, Department of Nutrition and Dietetics. Master Thesis, İstanbul, 2011.

[21] Şanlıer, N., Konaklığlu, E.,Güçer, E. The relationship between nutrition knowledge, habits and behaviors of young people and body mass indexes. GU, Journal of Gazi Faculty 
of Education, Vol 29, No 2. 333-352, 2009.

[22] Karasu, Ö. Evaluation of nutrition knowledge and status of boarder and extern high school students, Gazi University, Institute of Educational Sciences, Department of Educational Sciences, Master Thesis, Ankara, 2006.

[23] Hellert, W.,Beghin, L., Henauw, S.D., Grammatikaki, E., Hallström, L., Manios, Y. Nutritional knowledge in European adolescents: results from the HELENA (Healthy Lifestyle in Europe by Nutrition in Adolescence) study. Public Health Nutrition: 14(12), 2083-2091, 2011.

[24] Ralph, M.A. Assessing the nutrition knowledge of young athletes: development of an evidence-based questionnaire. http://hdl.handle.net/10150/244514 08.03.2018, 2012.

[25] Çırak, O. Nutritional status and nutritional information of adolescent males engaged in sports in different branches. Ankara University, Institute of Health Sciences, Department of Nutrition and Dietetics, M.Sc. Thesis, Ankara, 2016.

[26] Gökdemir, K. Nutritional information and habits of wrestlers. Gazi University, Bes. Bi. Der. Volume (2) 18-29, 1996.

[27] Şimşek, H. A research on the nutrition knowledge and habits of secondary school students. Gazi University, Institute of Social Sciences, Master Thesis, Ankara, 1991.

[28] Heydenreich, J., Carlsohn, A. and Mayer, F. Nutrition knowledge and food choice in young athletes. Research Article. 1-12, 2014.

[29] Manore, M. M., Patton-Lopez, M. M., Meng, Y. and Wong, S. S. Sport Nutrition Knowledge, Behaviors and Beliefs of High School Soccer Players, Nutrients, 9, 350; doi:10.3390/nu9040350, 2017.

[30] Demir, S. Examination of the nutrition knowledge levels and habits of the students in the school teams of the high schools in Sirnak province. Ağrı İbrahim Ceçen University, Institute of Social Sciences, Department of Physical Education and Sports, Movement and Training, M.Sc. Thesis, Şırnak, 2017.

[31] Sagun, P. Measurement of nutrition knowledge and habits of final years' students of high schools in different socio-cultural environments. Hacettepe University, Institute of Health Sciences, Department of Nutrition and Dietetics. MA thesis, Ankara, 1987.

[32] Sadhu, A. R. and Kotwal, D., Knowledge-Attitude-Practice (KAP) Study and Nutrition Education of Athletic and Non-athletic Teenagers (13-18 Years). Ergonomics in Caring for People Proceedings of the International Conference on Humanizing Work and Work Environment, ISBN 978-981-10-4980-4 (eBook) https://doi.org/10.1007/ 978-981-10-4980-4, Page.73-82, 2015.

[33] Dallongeville, J., Marecaux, N., Cottel D. Association between nutrition knowledge and nutritional intake in middle-aged men from Northern France. Public Health Nutr. 4: 27-33, 2001 .

[34] Yücel, B. An Investigation of Nutritional Habits and Nutritional Knowledge Levels of Healthcare Staff. Başkent University Institute of Health Sciences, Department of Nutrition and Dietetics, M.Sc. Thesis, Ankara, 2015.

[35] Meng, Y., Manore, M. M., Schuna, J.M., Patton-Lopez, M.M., Branscum, A. and Wong, S. S., Promoting Healthy
Diet, Physical Activity, and Life-Skills in High School Athletes: Results from the WAVE Ripples for Change Childhood Obesity Prevention Two-Year Intervention. Nutrients, 10, 947; doi:10.3390/nu10070947.2018.

[36] Laram'ee, C., Drapeau, V., Valois, P., Goulet, C., Jacob, R., Provencher, V., Lamarche, B., Evaluation of a Theory-Based Intervention Aimed at Reducing Intention to Use Restrictive Dietary Behaviors Among Adolescent Female Athletes. Journal of Nutrition Education and Behavior, Volume 49, Number 6, 2017. 